\title{
Highly stable visible-light photocatalytic properties of black rutile TiO2 hydrogenated in ultrafast flow
}

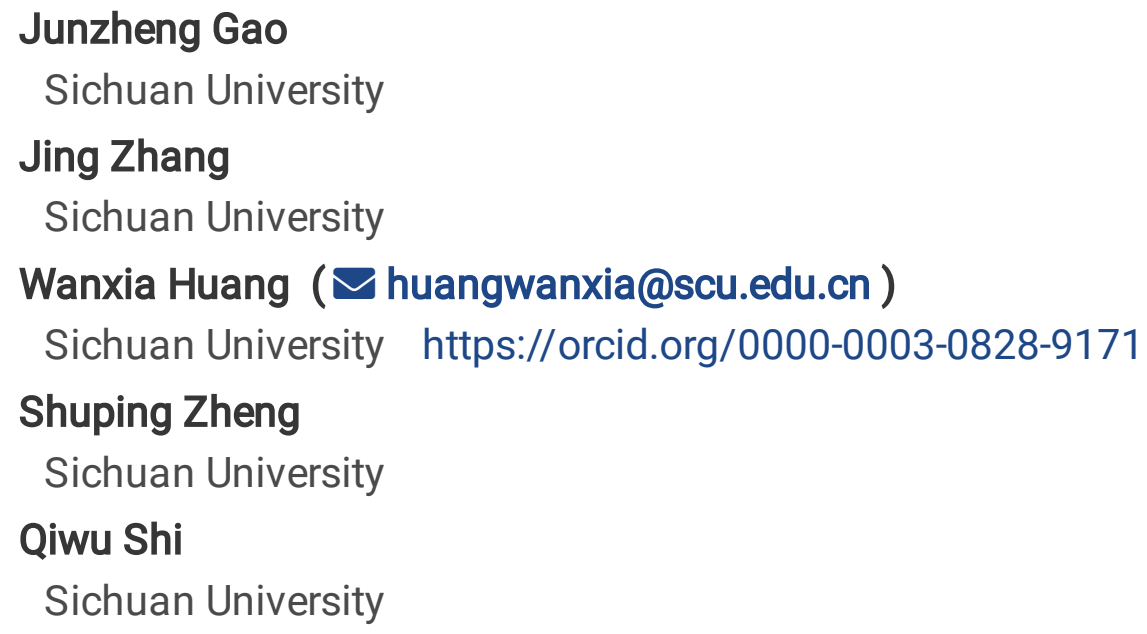

Original Research

Keywords: black rutile $\mathrm{TiO} 2$, visible-light photocatalysis, oxygen vacancies, ultrafast hydrogen flow, stability

Posted Date: February 12th, 2021

DOl: https://doi.org/10.21203/rs.3.rs-206597/v1

License: (c) (i) This work is licensed under a Creative Commons Attribution 4.0 International License. Read Full License 


\section{Abstract}

The hydrogenation and introducing oxygen vacancies $\left(\mathrm{V}_{0}\right)$ can lead to surface lattice-disorder in $\mathrm{TiO}_{2}$, which is a new form of $\mathrm{TiO}_{2}$ named black $\mathrm{TiO}_{2}$, with excellent visible-light photocatalytic activity, but this $\mathrm{TiO}_{2}$ is easy to failure because oxidation makes the concentration of surface $V_{0}$ decrease rapidly in a short time. In this work, black $\mathrm{TiO}_{2}$ nanoparticles with $\mathrm{V}_{\mathrm{O}}$ almost concentrated inside nanoparticles were fabricated under ultrafast hydrogen flow. These bulk $\mathrm{V}_{\mathrm{O}}$ shortened the bandgaps of black $\mathrm{TiO}_{2}$, enhanced its visible light absorption, and meanwhile provided extremely strong stability. A series of characterization methods confirmed the location of $\mathrm{V}_{0}$, and degradation experiments on $\mathrm{Cr}^{6+}$ or rhodamine $\mathrm{B}$ demonstrated the good visible-light photocatalytic performance of our material. After 18 months of natural aging treatment (in the air), our samples showed no discoloration and maintained $89.5 \%$ photocatalytic efficiency, and further study exhibited that this black $\mathrm{TiO}_{2}$ also contained excellent acidresistance and moderate alkaline-resistance. This work could help design lattice-disorder to obtain more stable and practical black $\mathrm{TiO}_{2}$.

\section{Introduction}

$\mathrm{TiO}_{2}$ has been widely studied in dealing with environmental and energy problems since its photocatalytic property of decomposing water was discovered in 1972 [1-3]. However, naturally occurring $\mathrm{TiO}_{2}$ can only be excited by ultraviolet to generate electron-hole pairs owing to its wide bandgap and weak visible-light absorbance [4, 5]; this limitation makes $\mathrm{TiO}_{2}$ a long distance to practical application. Doping [6, 7], compounding with other semiconductor oxides [8], such methods have been tried for narrowing the bandgap of $\mathrm{TiO}_{2}$ and enhancing its visible-light photocatalytic performance.

In 2011, Chen etal. reported a material called "black $\mathrm{TiO}_{2}$ " with an amazing narrowed bandgap (1.54 eV) and significantly improved visible-light photocatalytic activities compared to white $\mathrm{TiO}_{2}$ [9], quickly attracting public eyes. These $\mathrm{TiO}_{2}$ nanoparticles changed from white to black after being reduced in a hydrogen atmosphere with high pressure, but their phase kept $\mathrm{TiO}_{2}$. This form of $\mathrm{TiO}_{2}$ had significant absorption of visible light, and in subsequent reports $\mathrm{TiO}_{2}$ with a similar mechanism but slightly lighter color was also called black $\mathrm{TiO}_{2}[10,11]$. Although many methods for the preparation of black $\mathrm{TiO}_{2}$ have been developed [12-14], hydrogenation remains the most used method for the reason of high-efficiency and ease of industrial production. Extensive efforts had been done on the formation mechanism of black $\mathrm{TiO}_{2}[13,15-17]$, while the most generally accepted explanation was that oxygen vacancies $\left(V_{0}\right)$ played a leading role in forming black $\mathrm{TiO}_{2}$. $\mathrm{V}_{\mathrm{O}}$ could change band structures and visible-light absorbance of black $\mathrm{TiO}_{2}$ via introducing donor energy levels in conduction bands $[9,17-19]$. The generation of $\mathrm{V}_{\mathrm{O}}$ was often considered to be accompanied by the appearance of $\mathrm{Ti}^{3+}[20,21]$, and they could both promote the separation of photogenerated electron-hole pairs. Other defects such as surface hydroxyl groups had also been reported to be responsible for the formation of black $\mathrm{TiO}_{2}$ with its excellent visible-light photocatalytic performance. Moreover, these crystal defects often accumulated on the material surface, 
resulting in surface disorder and thus typical amorphous shells could be usually observed on the surface of black $\mathrm{TiO}_{2}$.

Although the ability of black $\mathrm{TiO}_{2}$ to utilize visible light had been dramatically improved, the surface defects were easy to be oxidized, leading to a degradation concentration of defects so black $\mathrm{TiO}_{2}$ were instable, serious constraining to its further application [22, 23]. Some researchers began to concern and solve this problem, while the photocatalytic performance of black $\mathrm{TiO}_{2}$ long treated under various external risk factors $\left(\mathrm{O}_{2}, \mathrm{H}^{+}, \mathrm{OH}^{-}\right.$, etc.) was still not investigated. For example, Lan et al. adopted an in-situ reduction method to form $\mathrm{Ti}^{3+}$ as much as possible inside the material to stabilize black $\mathrm{TiO}_{2}$ [23]. At the same time, one study revealed that there are two types of $\mathrm{V}_{0}$ and they may correspond to different locations [24].

Herein, black rutile $\mathrm{TiO}_{2}$ nanoparticles with stable visible-light photocatalytic activity were prepared through hydrogen in an ultrafast flow. A series of temperature gradient experiments were carried out to found an optimal parameter and the samples hydrogenated at $800^{\circ} \mathrm{C}$ contained the best photocatalytic properties. Various characterization methods revealed good surface crystallization but a mass generation of $\mathrm{V}_{\mathrm{O}}$ in the body of black $\mathrm{TiO}_{2}$, and the high concentration of internal defects rather than surface defects was believed to an important cause of stabilizing black $\mathrm{TiO}_{2}$. The natural aging process of 18 months indicated 3 times longer shelf life of our samples than traditional black $\mathrm{TiO}_{2}$, besides, an acid-alkali resistance experiment further investigating the stability of black $\mathrm{TiO}_{2}$.

\section{Experiment \\ 2.1 materials}

White rutile $\mathrm{TiO}_{2}$ (50 nm in diameter, provided by Ansteel Research Institute of Vanadium and Titanium) was heated in nitrogen flow inside a furnace with a $10^{\circ} \mathrm{C} / \mathrm{min}$ heating rate firstly. After the furnace temperature reached $150^{\circ} \mathrm{C}$, nitrogen was replaced with ultrafast pure hydrogen flow $(99.9 \%, 1.2 \mathrm{~L} / \mathrm{min})$, and then they were held at different temperatures $\left(700-900^{\circ} \mathrm{C}\right)$ for $1 \mathrm{~h}$. Black $\mathrm{TiO}_{2}$ was obtained after the samples cooled to room temperature. In the following, black $\mathrm{TiO}_{2}$ hydrogenated at different temperatures was abbreviated to $700^{\circ} \mathrm{C}-\mathrm{H}-\mathrm{TiO}_{2}, 750^{\circ} \mathrm{C}-\mathrm{H}-\mathrm{TiO}_{2}$, etc.

\section{2 photocatalytic test}

$4 \mu \mathrm{mol} / \mathrm{L}$ Rhodamine B (RhB, provided by ChengDu Chron Chemicals Co,.Ltd) aqueous solutions were the reaction substrate of most photocatalytic experiments. In each experiment, $10 \mathrm{mg} \mathrm{\textrm {TiO } _ { 2 }}$ nanoparticles were dispersed into a $250 \mathrm{~mL} \mathrm{RhB}$ solution. After the mixture reached an adsorption-elution balance in the dark, visible-light photocatalytic experiments were carried out under a xenon lamp whose ultraviolet light had been cut. $5 \mathrm{~mL}$ mixture was taken for filtration and centrifugation each time, and then the 
absorbance of supernatants was measured to determine the concentration of RhB. The parameters of stability experiments under different environments would be described later in this article.

\subsection{Characterization}

The colors of black $\mathrm{TiO}_{2}$ gradually deepened with hydrogenation temperature increasing, which matched with the ultraviolet-visible diffuse reflectance spectra (UV-Vis DRS, measured on Shimadzu UV-3600). The phase analysis was obtained by an X-ray diffraction spectrometer (XRD, Rigaku smartlab9) with Cu Ka Xray. Electron paramagnetic resonance (EPR) was carried out at $77 \mathrm{~K}$ on a Bruker ELEXSYS-II E500 spectrometer. The information about surface hydroxyls and Ti states were obtained by an X-ray photoelectron spectrometer (XPS, Thermo Fisher Scientific K-Alpha). Microphotographs of materials were obtained by scanning electron microscopy (SEM, FEI Inspect F50) and transmission electron microscopy (TEM, FEl Tecnai G2 F20).

\section{Results And Discussion}

Fig. 1 illustrated the XRD patterns (normalization based on the intensity of diffraction peak (110)) of different $\mathrm{TiO}_{2}$. The main phase of samples hydrogenated at different temperatures all maintained rutile $\mathrm{TiO}_{2}$, and no obvious change was observed among $700^{\circ} \mathrm{C}-\mathrm{H}-\mathrm{TiO}_{2}, 750^{\circ} \mathrm{C}-\mathrm{H}-\mathrm{TiO}_{2}, 800^{\circ} \mathrm{C}-\mathrm{H}-\mathrm{TiO}_{2}$, and white $\mathrm{TiO}_{2}$. Higher hydrogenation temperatures led to the formation of suboxide titanium, reflecting as tiny splits in the main diffraction peak $\left(27.4^{\circ}\right)$, and a reconstruction process induced by titanium suboxides during reduction processes brought other effects which were detailed discussed in supporting information $[25,26]$.

The information about appearance, absorbance, and bandgaps of different $\mathrm{TiO}_{2}$ was given in Fig. 2 . According to Fig. 2a, the colors of black $\mathrm{TiO}_{2}$ were gradually darkened as hydrogenation temperatures went up. The deepening of colors brought photocatalysis marked significance that visible light could not be absorbed by white $\mathrm{TiO}_{2}$ but black $\mathrm{TiO}_{2}$ broke through this limitation. The UV-Vis DRS showed in Fig. $2 \mathrm{~b}$ exhibited a similar result that the visible-light absorbance of white $\mathrm{TiO}_{2}$ was almost 0 , while black $\mathrm{TiO}_{2}$ had significantly stronger absorbance proportional to hydrogenation temperatures. The values of bandgaps shown in Fig. $2 c$ were obtained by mathematical processing Fig. $2 b$ and the following equation:

$$
\alpha h v=A\left(h v-E_{g}\right)^{2}
$$

Here, $a, v$, and $E_{g}$ represented absorption coefficient, frequency, and bandgaps respectively. This formula was the main calculation method of black $\mathrm{TiO}_{2}$ bandgap and was widely used by researchers $[27,28]$. The bandgap of white $\mathrm{TiO}_{2}$ (rutile) in our experiments was $2.94 \mathrm{eV}$ which was closed to experienced data 3.0 $\mathrm{eV}$, while black $\mathrm{TiO}_{2}$ had constantly narrowing bandgaps with hydrogenation temperatures raising. $800^{\circ} \mathrm{C}-\mathrm{H}-\mathrm{TiO}_{2}$ had a markedly narrowed bandgap of $2.71 \mathrm{eV}$, and furtherly the bandgap of $900^{\circ} \mathrm{C}-\mathrm{H}-\mathrm{TiO}{ }_{2}$ 
was down to $2.05 \mathrm{eV}$. These characteristics indicated that white $\mathrm{TiO}_{2}$ nanoparticles were successfully transformed to black $\mathrm{TiO}_{2}$.

Fig. 3 presented the micromorphology information of black $\mathrm{TiO}_{2}$ hydrogenated under different temperatures. White $\mathrm{TiO}_{2}$ nanoparticles without treatment were in the shape of spindles with a lengthdiameter of nearly $50 \mathrm{~nm}$, while black $\mathrm{TiO}_{2}$ nanoparticles were ellipsoidal in obvious sphericity due to the thermal effect in annealing processes, and the size of nanoparticles also slightly increases continuously with annealing temperature raising. In this paper, the nanoparticle sizes of different black $\mathrm{TiO}_{2}$ were mostly between $70-110 \mathrm{~nm}$, so the interference of large particle size on photocatalytic performance could be eliminated. The lattice-disordered shell was a significant feature of traditional black $\mathrm{TiO}_{2}$, which was interestingly not observed in our hydrogenated materials. Lattice stripes at the edge of black $\mathrm{TiO}_{2}$ nanoparticles were still clear, indicating quite low surface disorder and defect concentration. White $\mathrm{TiO}_{2}$ had an interplanar spacing of $0.319 \mathrm{~nm}$ in (110) face, while this parameter in black $\mathrm{TiO}_{2}$ expanded to $0.342 \mathrm{~nm}$. This $7.2 \%$ expansion was due to the existence of $\mathrm{V}_{0}$ enriched in the body of black $\mathrm{TiO}_{2}$, and subsequent analysis of crystal defects further verified this conclusion.

The photocatalytic activity of different $\mathrm{TiO}_{2}$ was determined by the time-depend residual of $\mathrm{RhB}$, as shown in Fig. 4. RhB itself did not degrade under visible light, so its concentration change was caused by the photocatalytic effect of black $\mathrm{TiO}_{2}$. When the different mixtures of $\mathrm{TiO}_{2}$ powders and $\mathrm{RhB}$ water solution had just been exposed to light, their absorption-dissociation balance reached in the dark would be disturbed, causing an abnormal upward change in the $\mathrm{C} / \mathrm{C}_{0}$ curve of RhB in the first 20 min and this phenomenon disappeared with time growth. As expected, white $\mathrm{TiO}_{2}$ had no visible-light photocatalytic activity due to its poor ability in utilizing visible light, while black $\mathrm{TiO}_{2}$ had obvious enhanced photocatalytic activity driven by visible light, further suggesting that black rutile $\mathrm{TiO}_{2}$ were successfully prepared. $\mathrm{RhB}$ degradation rates of black $\mathrm{TiO}_{2}$ increased with hydrogenation temperatures and visiblelight absorbance before $800^{\circ} \mathrm{C}$, but an abnormal phenomenon of sharply decreased photocatalytic activity was observed in the experiments of $850^{\circ} \mathrm{C}-\mathrm{H}-\mathrm{TiO}_{2}$ and $900^{\circ} \mathrm{C}-\mathrm{H}-\mathrm{TiO}_{2}$, although they had darker colors and narrower bandgaps. This anomaly could be attributed to the changes in crystal planes of different black $\mathrm{TiO}_{2}$ and the difference in photocatalysis induced by crystal planes $[29,30]$. This would be detailly discussed in supplemental information. In general, $800^{\circ} \mathrm{C}-\mathrm{H}-\mathrm{TiO}_{2}$ had the best performance that it could degrade more than $70 \% \mathrm{RhB}$ in 2 hours, and we also chose another substrate $\mathrm{Cr}^{6+}$ that was more difficult to decompose to further illustrate the excellent photocatalytic activity of our material, which was revealed in Fig S1.

$800^{\circ} \mathrm{C}-\mathrm{H}-\mathrm{TiO}_{2}$ was selected for more tests and a series of stability experiments because of its optimal performance, and we adopted EPR measurement to reveal the changes from white $\mathrm{TiO}_{2}$ to black $\mathrm{TiO}_{2}$ from the angle of lattice defects. As shown in Fig. $4 \mathrm{a}$, for $800^{\circ} \mathrm{C}-\mathrm{H}-\mathrm{TiO}_{2}$, a small peak at $\mathrm{g}=2.005$ indicated the generation of a small number of $\mathrm{V}_{0}[24,31]$, while the spectrum of white $\mathrm{TiO}_{2}$ with few crystal defects appeared horizontal. This result explained the variation in bandgaps and absorbance from 
white $\mathrm{TiO}_{2}$ to $800^{\circ} \mathrm{C}-\mathrm{H}-\mathrm{TiO}_{2} . \mathrm{V}_{\mathrm{O}}$ produced donor levels under the conduction band [17] and then extended the bottom of the conduction band downward, thereby narrowing bandgaps of black $\mathrm{TiO}_{2}$. It was worth noting that different $\mathrm{V}_{\mathrm{O}}$ peaks correspond to diverse positions of existence, and black $\mathrm{TiO}_{2}$ reported previously usually had the peaks at both nearly $\mathrm{g}=1.98$ (in the surface and in coexistence with $\mathrm{Ti}^{3+}$ ) and nearly $\mathrm{g}=2.005$ (in the body) [24], while the peak at $\mathrm{g}=1.98$ in $800^{\circ} \mathrm{C}-\mathrm{H}-\mathrm{TiO}_{2}$ in this paper seemed not obvious. This analysis meant that in $800^{\circ} \mathrm{C}-\mathrm{H}-\mathrm{TiO}_{2} \mathrm{~V}_{\mathrm{O}}$ was concentrated mainly inside nanoparticles. According to Fig. 5b, the double peaks at $458.7 \mathrm{eV}$ and $464.5 \mathrm{eV}$ in white $\mathrm{TiO}_{2}$ could be all assigned to $\mathrm{Ti}^{4+}$ [14]; the spectrum of $800^{\circ} \mathrm{C}-\mathrm{H}-\mathrm{TiO}_{2}$ showed a similar result that the total peak was almost identical to the $\mathrm{Ti}^{4+}$, also indicating that defects $\mathrm{Ti}^{3+}$ barely existed in the surface of black $\mathrm{TiO}_{2}$ nanoparticles. Fig. S2 further illustrated that only a few surface defects existed in our material, and those characteristics may contribute to the excellent stability of $800^{\circ} \mathrm{C}-\mathrm{H}-\mathrm{TiO}_{2}$.

VB-XPS spectra shown in Fig. $5 \mathrm{c}$ gave the levels of valance bands (VB) in different $\mathrm{TiO}_{2}$. For white $\mathrm{TiO}_{2}$, the maximum of VB (VBM) was at about $2.65 \mathrm{eV}$ toward the vacuum level, and $800^{\circ} \mathrm{C}-\mathrm{H}-\mathrm{TiO}_{2}$ had a similar VBM of $2.63 \mathrm{eV}$. The improvement effect of $\mathrm{V}_{\mathrm{O}}$ on black $\mathrm{TiO}_{2}$ was mainly through introducing donor levels in its conduction band (CB), so their valence band (VB)did not change significantly. The position of $\mathrm{CB}$ could be obtained by combining bandgaps with VB. The minimum of $\mathrm{CB}$ in white $\mathrm{TiO}_{2}$ was at $-0.29 \mathrm{eV}$, while that of $800^{\circ} \mathrm{C}-\mathrm{H}-\mathrm{TiO}_{2}$ was extended to $-0.08 \mathrm{eV}$. This change coincided with the generating of donor levels in the edge of $\mathrm{CB}$, so the bandgaps of black $\mathrm{TiO}_{2}$ were narrowed and the excitation driven by visible light was also promoted.

Fig. 6 gave the appearance and photocatalytic activity of $800^{\circ} \mathrm{C}-\mathrm{H}-\mathrm{TiO}_{2}$ after natural aging treatment for 18 months in the air atmosphere. As shown in $\mathrm{Fig} 6 \mathrm{a}, 800^{\circ} \mathrm{C}-\mathrm{H}-\mathrm{TiO}_{2}$ after 18 months of aging treatment still retained a typical appearance of black $\mathrm{TiO}_{2}$, with no significant difference from initial samples. Fig $6 \mathrm{~b}$ showed the comparison of photocatalytic performance of $800^{\circ} \mathrm{C}-\mathrm{H}-\mathrm{TiO}_{2}$ before and after aging treatment. $800^{\circ} \mathrm{C}-\mathrm{H}-\mathrm{TiO}_{2}$ after aging treatment could degrade $65.3 \% \mathrm{RhB}$ in $2 \mathrm{~h}$, and its photocatalytic activity was only $10.5 \%$ lower than that of the samples before aging treatment, indicating that our black $\mathrm{TiO}_{2}$ contains great stability and were only slightly oxidized after long-term storage in air. Corresponding to our works, black $\mathrm{TiO}_{2}$ mainly depending on surface $\mathrm{V}_{0}$ experienced a similar degree of photocatalytic performance attenuation in only 6 months [22]. The circulation experiment result of $800^{\circ} \mathrm{C}-\mathrm{H}-\mathrm{TiO}_{2}$ after aging treatment was shown in Fig. 6c. Residual efficiency was calculated by the following equation:

\section{Residual efficiency $=\left(1-C_{y} / C_{0 y}\right) /\left(1-C_{x} / C_{0 x}\right)$.}

The suspension (include the part which was used to measure absorbance) during catalytic experiments was all collected, after that, black $\mathrm{TiO}_{2}$ powder was filtered from the suspension, cleaned in ultrasonic, and dried in argon. RhB concentration was correspondingly reduced in each subsequent cycle experiment due to the slight quality loss of catalyst, while other experimental parameters of photocatalysis were the 
same as those of Fig. 3. The photocatalytic activity of $800^{\circ} \mathrm{C}-\mathrm{H}-\mathrm{TiO}_{2}$ during 5 cycles of experiments did not change significantly, which further demonstrated its good storability.

To highlight the effect of $\mathrm{pH}$ on the material itself, the black $\mathrm{TiO}_{2}$ powders were pretreated with acid-base instead of directly being put into reaction solutions with different $\mathrm{pH}$ as commonly used. Aqueous solutions with different $\mathrm{pH}$ were regulated by $\mathrm{HCl}$ or $\mathrm{NaOH}$, and then the $800^{\circ} \mathrm{C}-\mathrm{H}-\mathrm{TiO}_{2}$ powder after 18 months of aging treatment was dispersed in different water for $180 \mathrm{~h}$, respectively. The parameters of subsequent processes were the same as above, and relevant results were shown in Fig. 7. Long-term immersion in acid solution did not decrease the photocatalytic activity of black $\mathrm{TiO}_{2}$, even that the photocatalytic activity of black $\mathrm{TiO}_{2}$ was improved due to changes in surface states driven by protonation [32]. A large number of $\mathrm{H}^{+}$interacted with black $\mathrm{TiO}_{2}$ for a long time, which might improve the absorption capacity of materials to RhB and thus increased their photocatalytic activity. The alkali group gave results of slightly reduced photocatalytic properties of black $\mathrm{TiO}_{2}$ after being placed in alkali solutions for a long time. In the group of $\mathrm{pH}=8,800^{\circ} \mathrm{C}-\mathrm{H}-\mathrm{TiO}_{2}$ remained $91.4 \%$ photocatalytic activity after $180 \mathrm{~h}$ treatment, and $800^{\circ} \mathrm{C}-\mathrm{H}-\mathrm{TiO}_{2}$ had nearly $80 \%$ residual efficiency after being immersed for $180 \mathrm{~h}$ at a stronger alkali solution of $\mathrm{pH}=10$ or 12 . The logarithmic diagram in Fig. $7 \mathrm{c}$ showed that the photocatalytic reactions of black $\mathrm{TiO}_{2}$ before and after treatment were all first-order reactions. In conclusion, our black $\mathrm{TiO}_{2}$ had excellent acid resistance, while when they were long-term used in alkali water, a little risk of performance decrease may be concerned.

\section{Conclusions}

In summary, black rutile $\mathrm{TiO}_{2}$ with extremely stable visible-light photocatalytic performance was effectively prepared in this work. $800^{\circ} \mathrm{C}-\mathrm{H}-\mathrm{TiO}_{2}$ had the best photocatalytic activity and the high concentration of bulk $\mathrm{V}_{\mathrm{O}}$ may be responsible for its enhanced visible-light photocatalytic activity and stability. The stability experiment for $800^{\circ} \mathrm{C}-\mathrm{H}-\mathrm{TiO}_{2}$ illustrated that our black $\mathrm{TiO}_{2}$ could maintain photocatalytic activity for 18 months, and also could be stably used in acidic water.

\section{Declarations}

\section{Acknowledgements}

This work was supported by the National Natural Science Foundation of China (Nos. 61771327), NSFC (Nos. U1730138 and U1930123), Science and Technology Project of Sichuan Province (19ZDYF2180), and the Fundamental Research Funds for Central Universities.

\section{Conflicts of interest/Competing interests}

There is no conflict of interest or competing interests to declare that are relevant to the content of this article. 
Availability of data and material

The source of the chemical, the process of the experiment, the handling of the data, etc., are transparent.

\section{Code availability}

The software application used in this work was also available on other computers.

\section{References}

1. Fujishima, K. Honda, Electrochemical photolysis of water at a semiconductor electrode. Nature 238 37-38 (1972)

2. Altomare, M. Pozzi, M. Allieta, L. G. Bettini, E. Selli, $\mathrm{H}_{2}$ and $\mathrm{O}_{2}$ photocatalytic production on $\mathrm{TiO}_{2}$ nanotube arrays: effect of the anodization time on structural features and photoactivity. Appl. Catal. B-Environ. 136-137 81-88 (2013)

3. Xu, Y. Le, B. Cheng, C. Jiang, Effect of calcination temperature on formaldehyde oxidation performance of $\mathrm{Pt} / \mathrm{TiO}_{2}$ nanofiber composite at room temperature. Appl. Surf. Sci. 426 333-341 (2017)

4. O. Scanlon, C. W. Dunnill, J. Buckeridge, S. A. Shevlin,A. J. Logsdail, S. M. Woodley, C. R. A. Catlow, M. J. Powell, R. G. Palgrave, I. P. Parkin, G. W. Watson, T. W. Keal, P. Sherwood, A. Walsh, Band alignment of rutile and anatase $\mathrm{TiO}_{2}$. A. A. Sokol, Nat. Mater. 12 798-801 (2013)

5. K. Allam, M. A. El-Sayed, Photoelectrochemical water oxidation characteristics of anodically fabricated $\mathrm{TiO}_{2}$ nanotube arrays: structural and optical properties. J. Phys. Chem. C $11412024-$ 12029 (2010)

6. Jiang, Z. Luo, Y. Li, W. Wang, J. Li, J. Li, Y. Ao, J. He, V. K. Sharma, J. Wang, Morphology- and phasecontrolled synthesis of visible-light-activated $\mathrm{s}$ doped $\mathrm{TiO}_{2}$ with tunable $\mathrm{S}^{4+} / \mathrm{S}^{6+}$ ratio. Chem. Eng. J. 402125549 (2020)

7. O. Amor, K. Elghniji, E. Elaloui, Improving charge separation, photocurrent and photocatalytic activities of Dy-doped $\mathrm{TiO}_{2}$ by surface modification with salicylic acid. J. Mater. Sci: Mater. Electron. $3120919-20931$ (2020)

8. Zheng, D. Li, X. Li, J. Chen, C. Cao, J. Fang, J. Wang, Y. He, Y. Zheng, Construction of $\mathrm{ZnO} / \mathrm{TiO}_{2}$ photonic crystal heterostructures for enhanced photocatalytic properties. Appl. Catal. B-Environ. 168169 408-415 (2015)

9. Chen, L. Liu, P. Y. Yu, S. S. Mao, Increasing solar absorption for photocatalysis with black hydrogenated titanium dioxide nanocrystals. Science 331 746-750 (2011)

10. Liu, C. Schneider, D. Freitag, M. Hartmann, U. Venkatesan, J. Müller, E. Spiecker, P. Schmuki, Black $\mathrm{TiO}_{2}$ nanotubes: cocatalyst-Free open-circuit hydrogen generation. Nano Lett. 14 3309-3313 (2014)

11. Tian, H. Cui, G. Zhu, W. Zhao, J. Xu, F. Shao, J. He, F. Huang, Hydrogen plasma reduced black $\mathrm{TiO}_{2}-\mathrm{B}$ nanowires for enhanced photoelectrochemical water-splitting. J. Power Sources 325 697-705 (2016) 
12. Carlson, C. Elliott, S. Walker, M. Misra, S. Mohanty, An effective, point-of-use water disinfection device using immobilized black $\mathrm{TiO}_{2}$ nanotubes as an electrocatalyst. J. Electrochem. Soc. $163 \mathrm{H} 395-\mathrm{H} 401$ (2016)

13. Jedsukontorn, T. Ueno, N. Saito, M. Hunsom, Facile preparation of defective black $\mathrm{TiO}_{2}$ through the solution plasma process: effect of parametric changes for plasma discharge on its structural and optical properties. J. Alloy. Compd. 726 567-577 (2017)

14. Wang, C. Yang, T. Lin, H. Yin, P. Chen, D. Wan, F. Xu, F. Huang, J. Lin, X. Xie, M. Jiang, Visible-light photocatalytic, solar thermal and photoelectrochemical properties of aluminium-reduced black titania. Energy Environ. Sci. 6 3007-3014 (2013)

15. Choi, S. I. Moon, T. Song, S. Kim, Hydrogen-free defects in hydrogenated black $\mathrm{TiO}_{2}$. Phys. Chem. Chem. Phys. 20 19871-19876 (2018)

16. B. Mo, Y. Bai, Q. Y. Xiang, Q. Li, J. O. Wang, K. Ibrahim, J. L. Cao, Band gap engineering of $\mathrm{TiO}_{2}$ through hydrogenation. Appl. Phys. Lett. 105202114 (2014)

17. Naldoni, M. Allieta, S. Santangelo, M. Marelli, F. Fabbri, S. Cappelli, C. L. Bianchi, R. Psaro, V. D. Santo, Effect of nature and location of defects on bandgap narrowing in black $\mathrm{TiO}_{2}$ nanoparticles. J. Am. Chem. Soc. 134 7600-7603 (2012)

18. Teng, M. Li, C. Gao, G. Zhang, P. Zhang, Y. Wang, L. Chen, E. Xie, Preparation of black $\mathrm{TiO}_{2}$ by hydrogen plasma assisted chemical vapor deposition and its photocatalytic activity. Appl. Catal. BEnviron. 148-149 339-343 (2014)

19. Selcuk, X. Zhao, A. Selloni, Structural evolution of titanium dioxide during reduction in high-pressure hydrogen. Nat. Mater. 17 923-928 (2018)

20. Deák, J. Kullgren, T. Frauenheim, Polarons and oxygen vacancies at the surface of anatase $\mathrm{TiO}_{2}$. Phys. Status Solidi-Rapid Res. Lett. 8 583-586 (2014)

21. Yuan, X. Wang, X. Liu, H. Ge, G. Yin, C. Dong, F. Huang, $\mathrm{Ti}^{3+}$-Promoted high oxygen-reduction activity of Pd nanodots supported by black titania nanobelts. Appl. Mater. Interfaces 8 27654-27660 (2016)

22. Katal, M. Salehi, M. H. Davood, A. Farahani, S. Masudy-Panah, S. L. Ong, J. Hu, Preparation of a new type of black $\mathrm{TiO}_{2}$ under a vacuum atmosphere for sunlight photocatalysis. ACS Appl. Mater. Interfaces 10 35316-35326 (2018)

23. Lan, R. Wang, Q. Wei, Y. Wang, A. Hong, P. Feng, D. Zhao, Stable $\mathrm{Ti}^{3+}$ Defects in Oriented Mesoporous Titania Frameworks for Efficient Photocatalysis. Angew. Chem. Int. Ed. 59 17676-17683 (2020)

24. Li, M. Zhang, Z. Guan, Q. Li, C. He, J. Yang, Synergistic effect of surface and bulk single-electrontrapped oxygen vacancy of $\mathrm{TiO}_{2}$ in the photocatalytic reduction of $\mathrm{CO}_{2}$. Appl. Catal. B-Environ. 206 300-307 (2017)

25. Warschkow, Y. Wang, A. Subramanian, M. Asta, L.D. Marks, Structure and local-equilibrium thermodynamics of the $c(2 \times 2)$ reconstruction of rutile $\mathrm{TiO}_{2}(100)$. Phys. Rev. Lett. 100086102 (2008) 
26. T. Park, M. H. Pan, V. Meunier, E. W. Plummer, Surface reconstructions of $\mathrm{TiO}_{2}(110)$ driven by suboxides. Phys. Rev. Lett. 96226105 (2006)

27. Singh, A. K. Manna, R. K. Soni, Bifunctional $\mathrm{Au}-\mathrm{TiO}_{2}$ thin films with enhanced photocatalytic activity and SERS based multiplexed detection of organic pollutant. J. Mater. Sci: Mater. Electron. $3016478-$ 16493 (2019)

28. X. Li, X. Wang, C. C. Wang, H. Fu, Y. Liu, P. Wang, C. Zhao, S-TiO $2 /$ UiO-66- $\mathrm{NH}_{2}$ composite for boosted photocatalytic $\mathrm{Cr}(\mathrm{VI})$ reduction and bisphenol a degradation under LED visible light. J. Hazard. Mater. 399123085 (2020)

29. Liu, H. G. Steinrück, A. Osvet, Y. Yang, P. Schmuki, Noble metal free photocatalytic $\mathrm{H}_{2}$ generation on black $\mathrm{TiO}_{2}$ : on the influence of crystal facets vs. crystal damage. Appl. Phys. Lett. 110072102 (2017)

30. Zhang, P. Liu, Z. Lu, G. Xu, X. Wang, L. Qian, H. Wang, E. Zhang, J. Xi, Z. Ji, One-step synthesis of rutile nano- $\mathrm{TiO}_{2}$ with exposed $\left\{\begin{array}{lll}1 & 1 & 1\end{array}\right\}$ facets for high photocatalytic activity. J. Alloy. Compd. 632 133-139 (2015)

31. Chen, Y. Fu, F. Sun, Z. Hu, X. Wang, T. Zhang, F. Zhang, X. Wu, H. Chen, G. Cheng, R. Zheng, Oxygen vacancies and phase tuning of self-supported black $\mathrm{TiO}_{2-\mathrm{X}}$ nanotube arrays for enhanced sodium storage. Chem. Eng. J. 400125784 (2020)

32. P. Fitts, M. L. Machesky, D. J. Wesolowski, X. M. Shang, J. D. Kubicki, G. W. Flynn, T. F. Heinz, K. B. Eisenthal, Second-harmonic generation and theoretical studies of protonation at the water/alpha$\mathrm{TiO}_{2}$ (110) interface. Chem. Phys. Lett. 411 399-403 (2005)

\section{Figures}




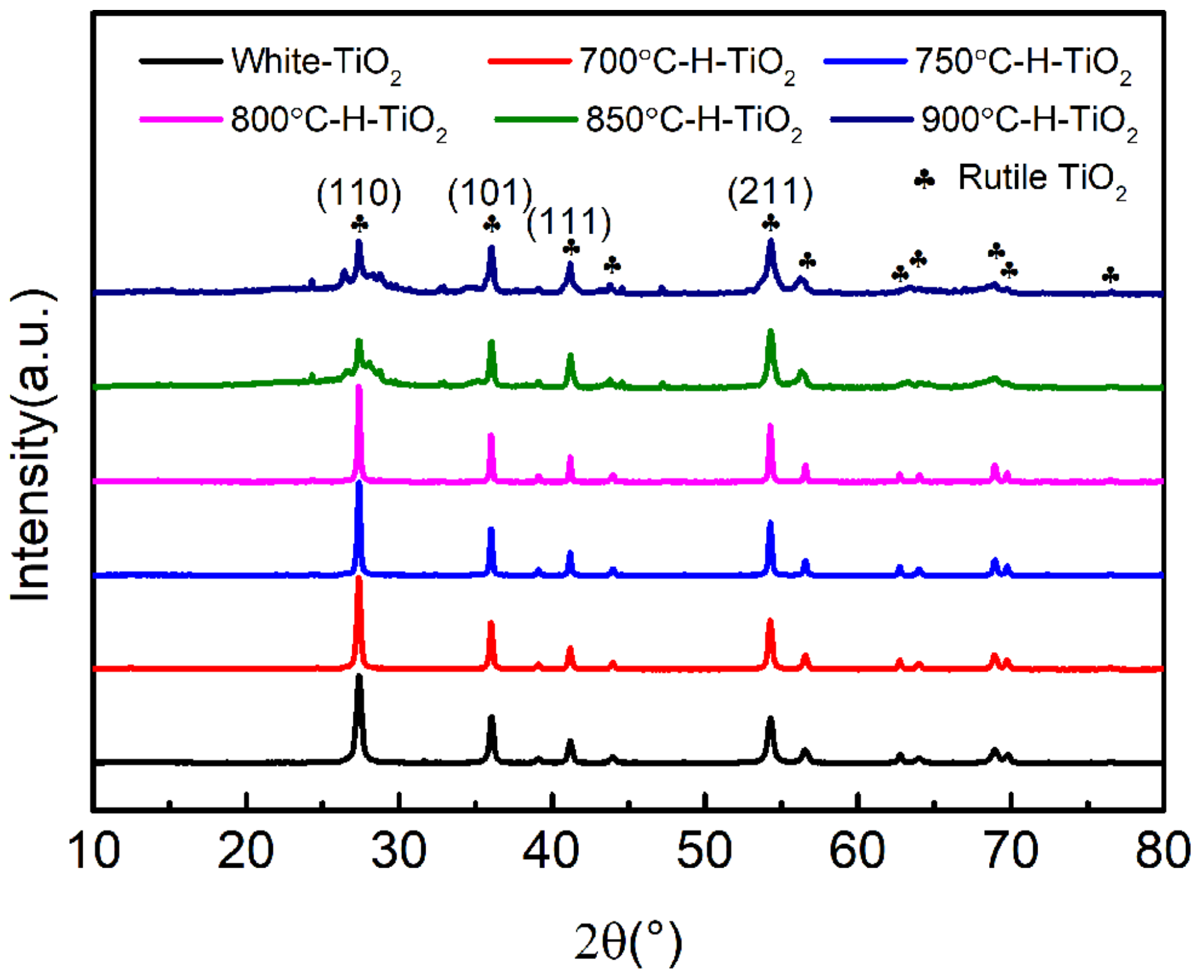

Figure 1

XRD spectra of white $\mathrm{TiO} 2$ and black $\mathrm{TiO} 2$ fabricated by hydrogenating at different temperatures 

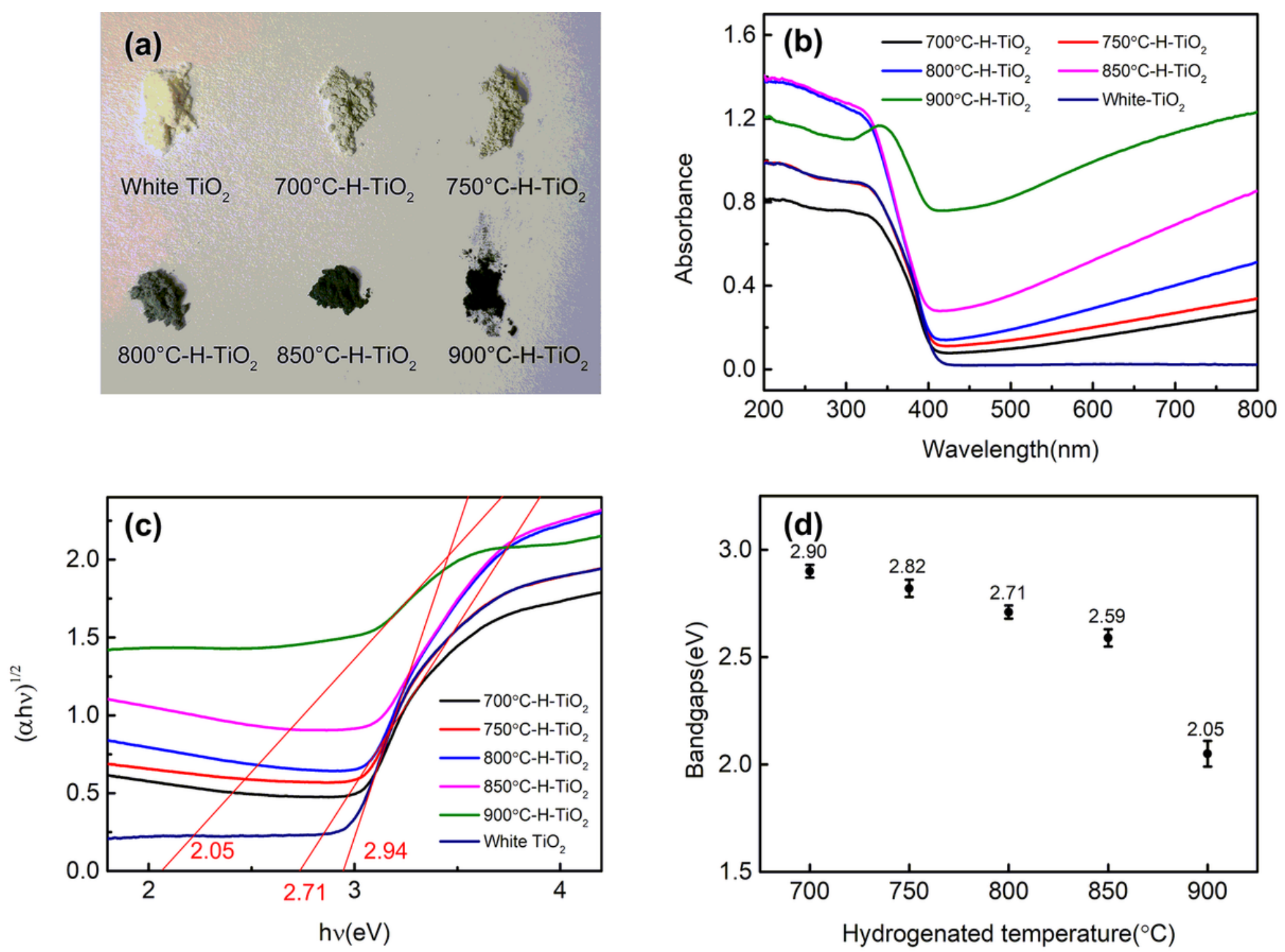

Figure 2

a Optical images of white $\mathrm{TiO} 2$ and black $\mathrm{TiO} 2$ fabricated by hydrogenating at different temperatures, $\mathrm{b}$ UV-Vis DRS spectra of white TiO2 and different black TiO2, c Mathematical processing data of b, $d$ Bandgaps varied with hydrogenation temperature 

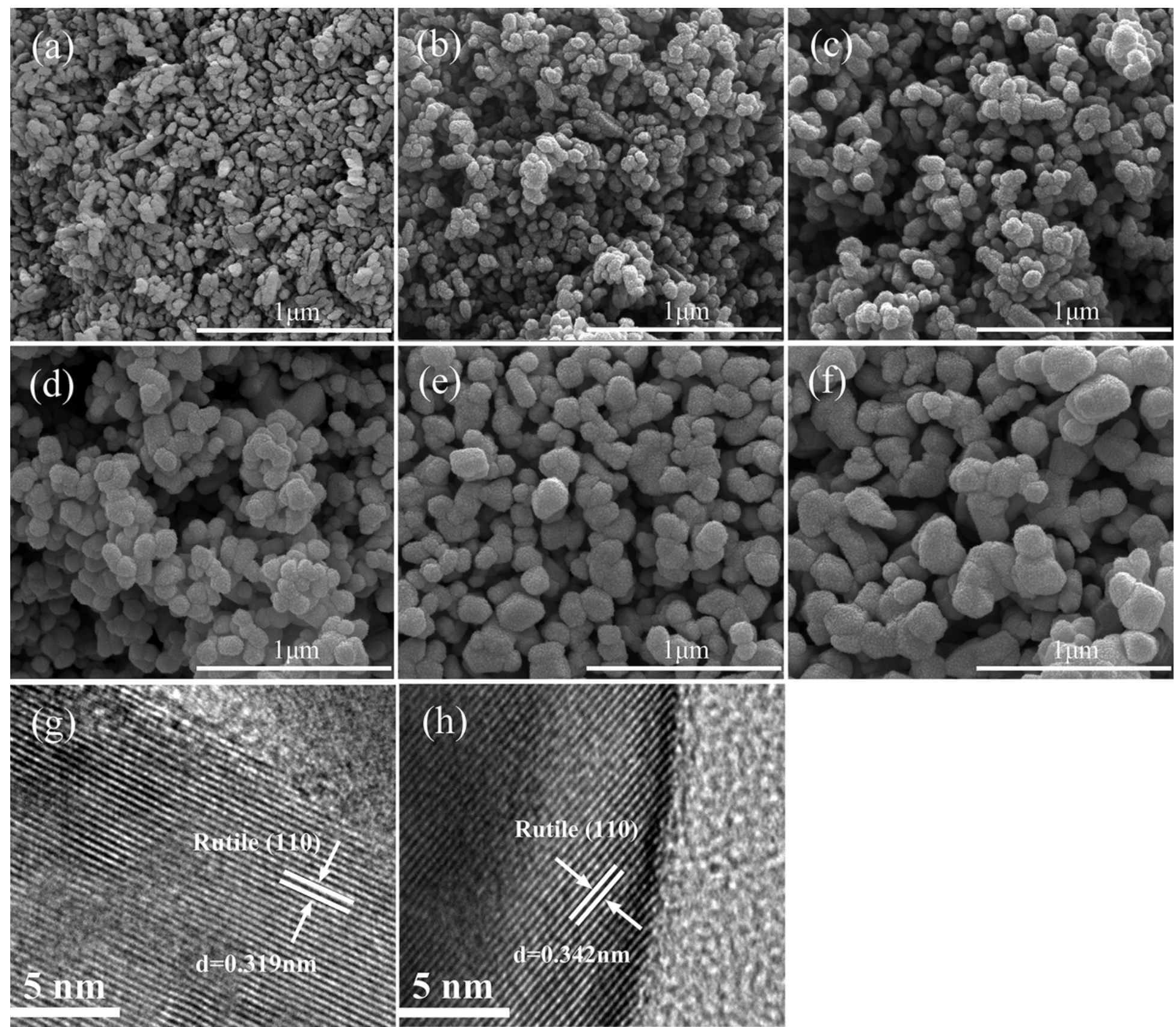

\section{Figure 3}

SEM images of a white $\mathrm{TiO} 2$, b $700^{\circ} \mathrm{C}-\mathrm{H}-\mathrm{TiO} 2, \mathrm{c} 750^{\circ} \mathrm{C}-\mathrm{H}-\mathrm{TiO} 2$, d $800^{\circ} \mathrm{C}-\mathrm{H}-\mathrm{TiO} 2$, e $850^{\circ} \mathrm{C}-\mathrm{H}-\mathrm{TiO} 2$, and $\mathrm{f}$ $900^{\circ} \mathrm{C}-\mathrm{H}-\mathrm{TiO} 2, \mathrm{HRTEM}$ images of $\mathrm{g}$ white TiO2 and $\mathrm{h} 800^{\circ} \mathrm{C}-\mathrm{H}-\mathrm{TiO} 2$ 

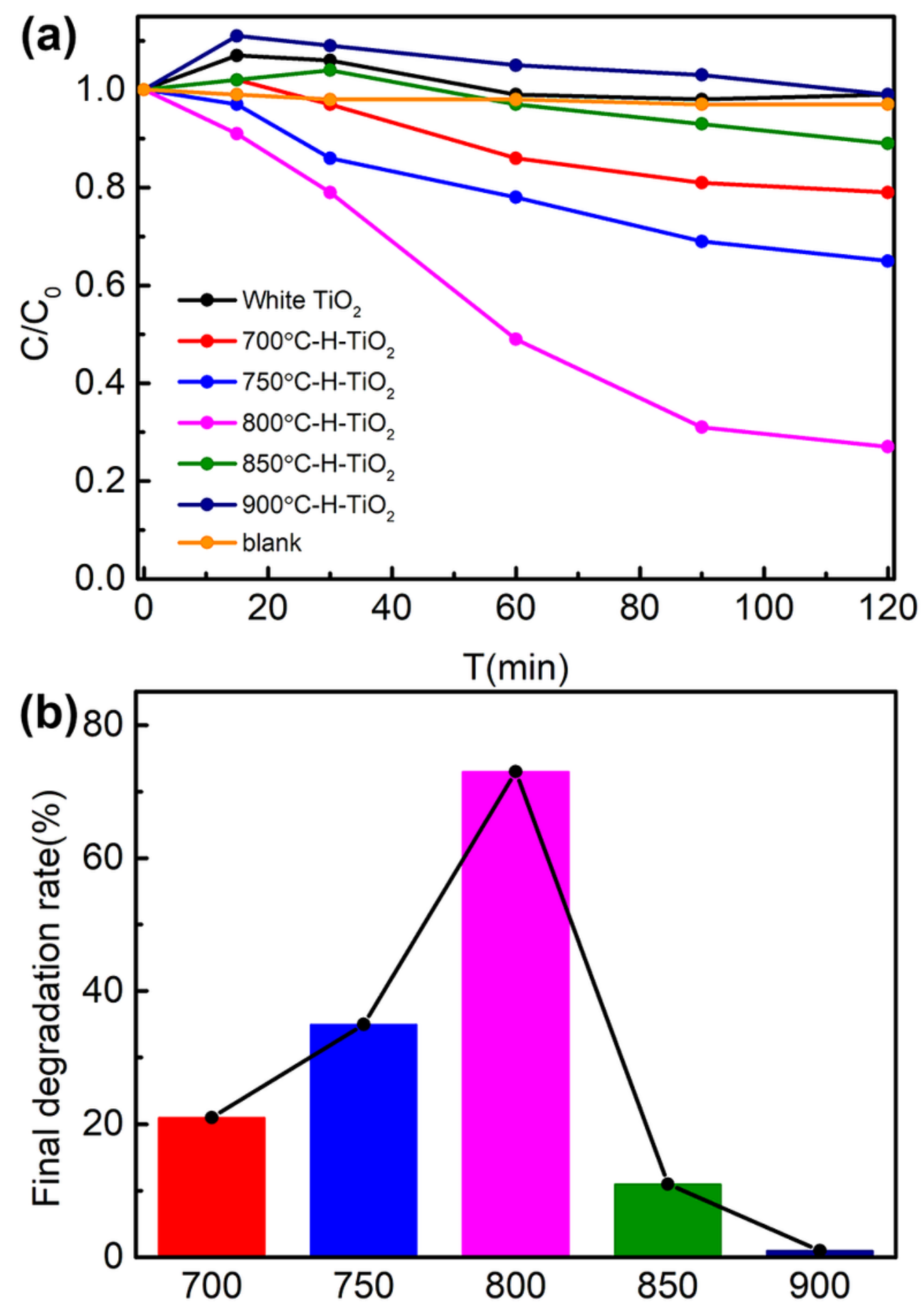

Hydrogenated temperature $\left({ }^{\circ} \mathrm{C}\right)$

Figure 4

a Time-dependent $\mathrm{RhB}$ residual in visible-light photocatalytic reactions of black $\mathrm{TiO} 2$ fabricated by hydrogenating at different temperatures and white $\mathrm{TiO} 2, \mathrm{~b}$ The degradation rate of $\mathrm{RhB}$ at the end of photocatalytic reaction of black $\mathrm{TiO} 2$ fabricated by hydrogenating at different temperatures 

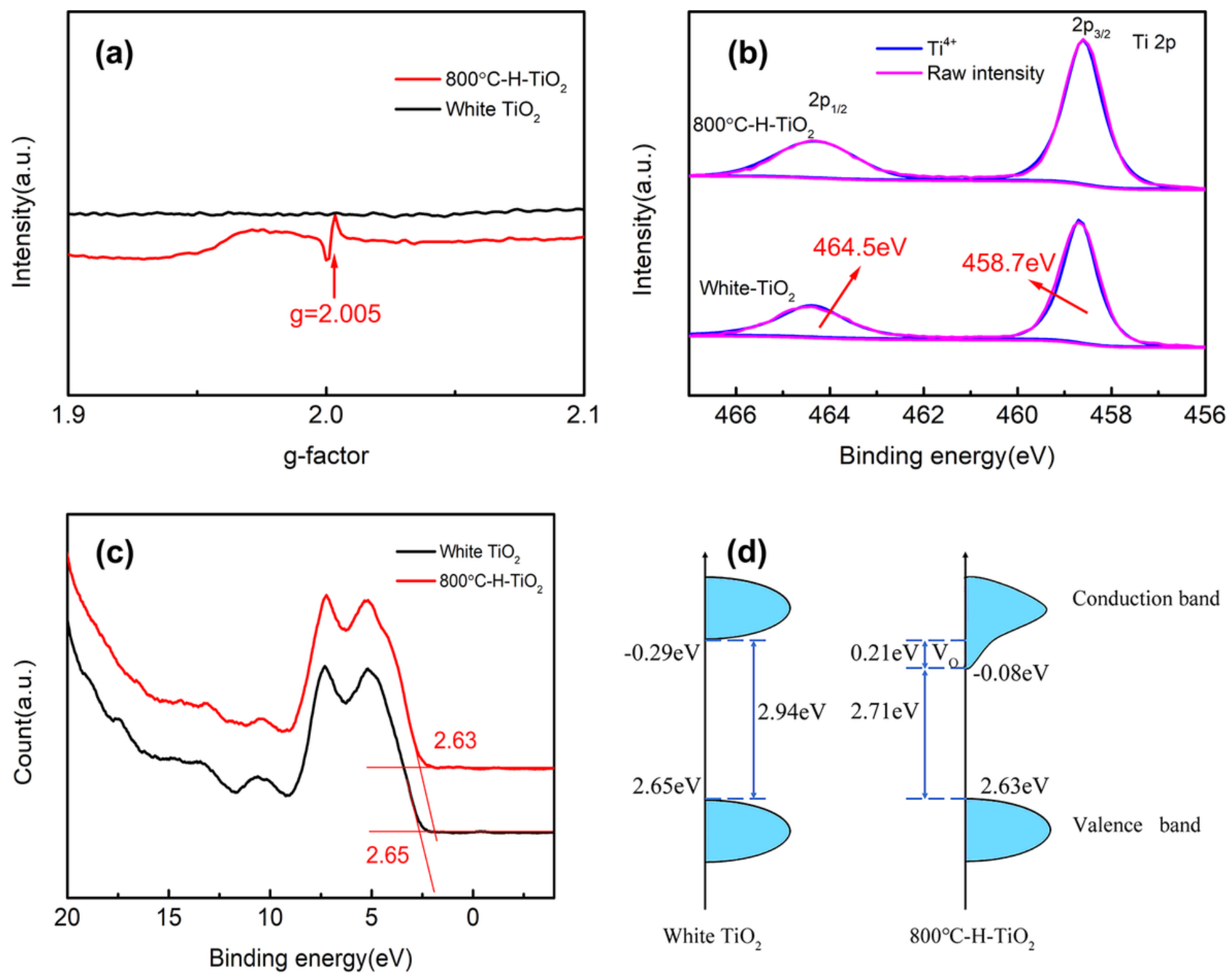

Figure 5

a EPR spectra and b XPS spectra (Ti 2p) of white TiO2 and $800^{\circ} \mathrm{C}-\mathrm{H}-\mathrm{TiO} 2, \mathrm{c}$ VB-XPS spectra of white $\mathrm{TiO} 2$ and $800^{\circ} \mathrm{C}-\mathrm{H}-\mathrm{TiO} 2, \mathrm{~d}$ Bandgap schematic of white $\mathrm{TiO} 2$ and $800^{\circ} \mathrm{C}-\mathrm{H}-\mathrm{TiO} 2$ 
(a)

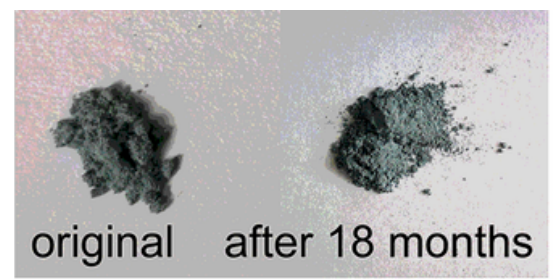

(b)

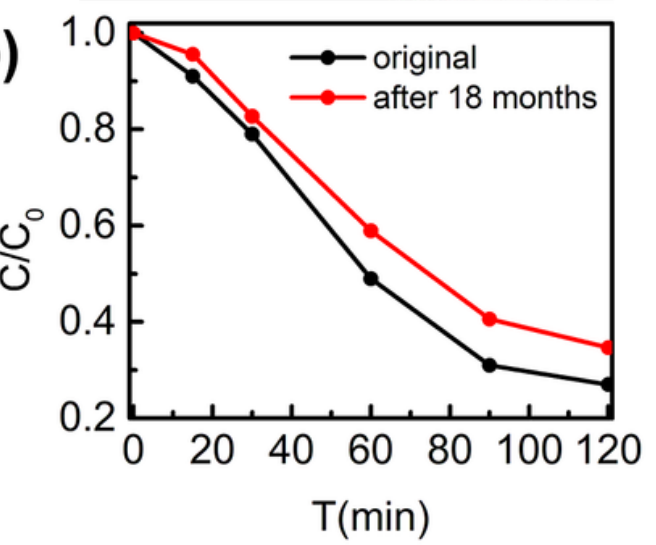

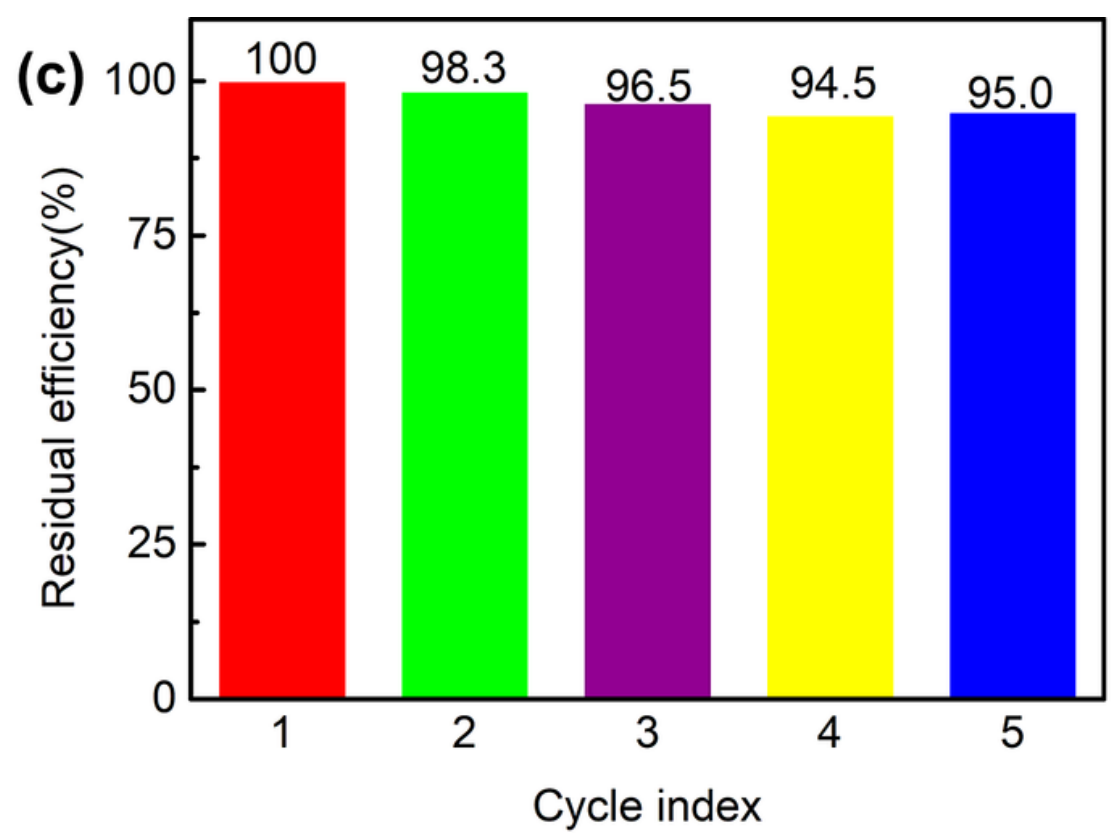

Figure 6

a Optical images of $800^{\circ} \mathrm{C}-\mathrm{H}-\mathrm{TiO} 2$ before and after 18 months of aging treatment, $\mathrm{b}$ RhB residual in visible-light photocatalytic reactions of $800^{\circ} \mathrm{C}-\mathrm{H}-\mathrm{TiO} 2$ (before and after 18 months of aging treatment), $\mathrm{C}$ RhB residual efficiency in cycle visible-light photocatalytic reactions of $800^{\circ} \mathrm{C}-\mathrm{H}-\mathrm{TiO} 2$ after 18 months of aging treatment
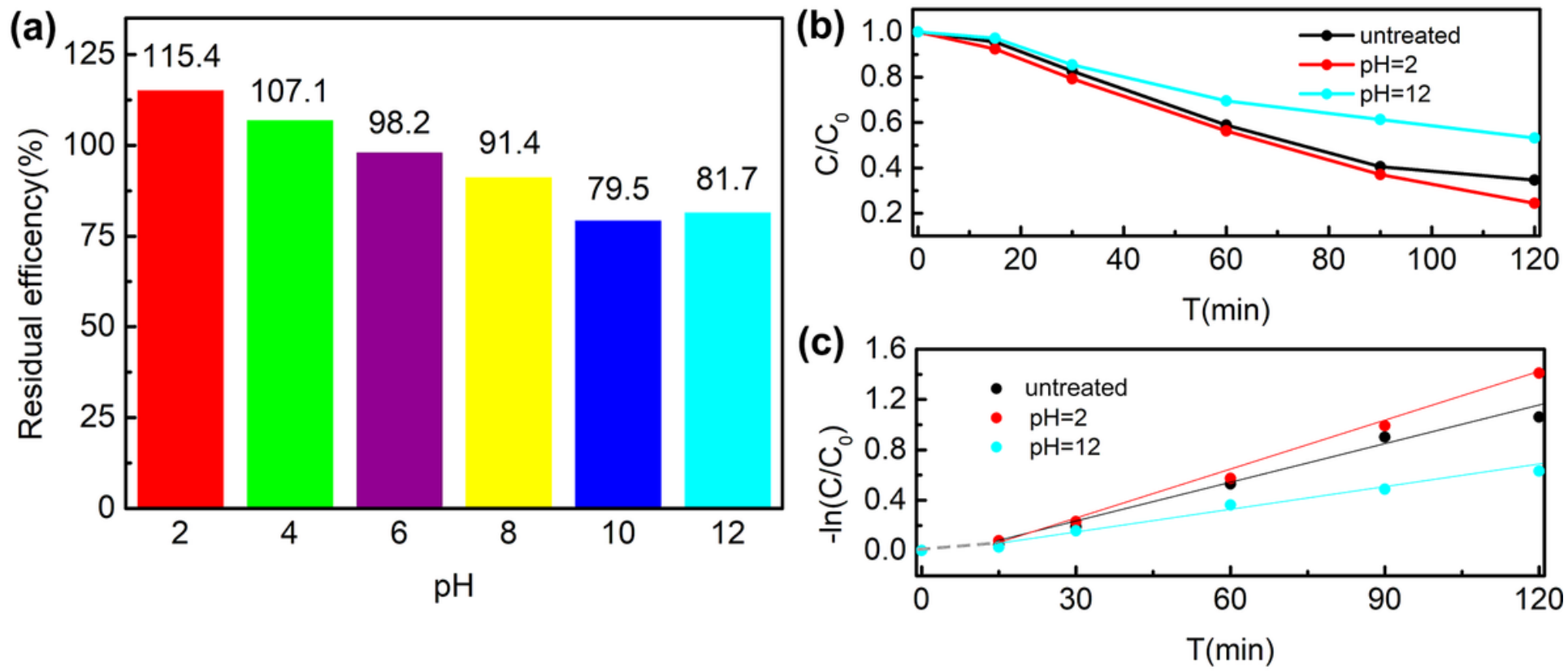

Figure 7

a RhB residual efficiency in visible-light photocatalytic reactions of $800^{\circ} \mathrm{C}-\mathrm{H}-\mathrm{TiO} 2$ which had been pretreated in various $\mathrm{pH}$ conditions $180 \mathrm{~h}$ (all black TiO2 were after 18 months of aging treatment, $\mathrm{b}$ $\mathrm{C} / \mathrm{CO}-\mathrm{T}$ curve of part experiments in a, $\mathrm{c}$ Logarithmic processing results of $\mathrm{b}$ 


\section{Supplementary Files}

This is a list of supplementary files associated with this preprint. Click to download.

- supplementalinformation.docx

- OnlineFig.S1.png

- OnlineFig.S2.png

- OnlineFig.S3.png

- OnlineFig.S4.png 